\title{
MEDICINA EN FEMENINO UNIVERSAL: EL SENTIDO DE LA ENFERMEDAD. UN VIAJE DEL ALMA, DE JEAN SHINODA BOLEN ${ }^{1}$
}

CONSUElO MiQueO

Universidad de Zaragoza

Recibido/15/07/2011

Aceptado/25/09/2011

\section{Referencia del libro comentado}

SHINODA BOLEN, Jean. El sentido de la enfermedad. Un viaje del alma, Barcelona, Kairós, 2006, 281 págs. Traducción de Antonio Francisco Rodríguez de la segunda edición inglesa de 200 (Closetothebone).

1. Jean Shinoda Bolen. El sentido de la enfermedad. Un viaje del alma, Barcelona, Kairós, 2006, 281 págs. Traducción de Antonio Francisco Rodríguez de la segunda edición inglesa de 2006 (Close to the bone). La misma editorial Kairós ha publicado una segunda edición en español en el año 2009.

Feminismo/s 18, diciembre 2011, pp. 309-321 


\section{Un espacio de confluencia}

El sentido de la enfermedad. Un viaje del alma es un libro que representa bien ese espacio de confluencia de dos corrientes del pensamiento y práctica feminista que han modelado nuestra época y profesión: el de las «expertas» sanitarias, bien integradas en la profesión que aman, y el de las críticas con la soberbia tecnificación de la medicina científica, defensoras muchas veces de los remedios naturales, la medicina integral o la tradición mística y de las brujas. Este libro permite entender, mejor que otros, la discusión intelectual y apuesta por la integración de la sabiduría tradicional femenina en la formación de los futuros médicos y médicas (quienes la necesitan mucho más que los demás profesionales sanitarios como fisioterapeutas, enfermeros o psicólogos), junto a las novedades de lo que llamamos «estudios de género y salud». Sirve para cuestionar, otra vez, con otros datos, el valor de la razón instrumental científica y las arraigadas creencias populares en los procesos de recuperación de la salud perdida. Y es, por último, un buen ejemplo para preguntarnos sobre el estilo femenino de escritura femenino y la raíz masculina del «estilo científico» estandarizado, y su relación con lo real existente.

Es probable que muchas mujeres y hombres lectores de Feminismo/s conozcan ya a esta significada autora, Jean Bolen, de quien se han publicado en español (casi siempre en la editorial Kairos) los siguientes títulos: Viaje a Avalon: la peregrinación de una mujer en la mitad de la vida (2000); Las brujas no se quejan (2004); El Tao de la Psicología (2005); Sabiduría concentrada para mujeres atrevidas (2006); El sentido de la enfermedad (2006, 2009); Mensaje urgente a las mujeres (2006); Las diosas de cada mujer. Una nueva psicología femenina (2007); Las diosas de la mujer madura. Arquetipos femeninos a partir de los cincuenta (2008); El millonésimo círculo. Cómo transformarnos a nosotras mismas y al mundo (2008); Los dioses de cada hombre (2009). En el caso de compartir estas lecturas, la reflexión que propongo puede generar resonancias -o disonancias- cognitivas y emotivas que deriven en discusión, nuevas observaciones o estudios de más largo alcance: el sueño de cualquier profesor o profesora. Pero es que, además, necesitamos normalizar en el medio académico el diálogo entre expertos y usuarios «el saber sobre la enfermedad» debido 
al limitado fundamento filosófico o epistemológico de nuestra canónica «medicina basada en la evidencia» (MBE), un reduccionismo mantenido sin duda por intereses industriales y, quizá, de género masculino.

Elegir este exitoso, interesante y problemático libro de una psiquiatra analista jungiana norteamericana y autora de best sellers ha supuesto, para mi, cruzar un umbral. Pudiendo elegir tantos otros de mi comunidad científica médica o histórica de los que hablar en el estilo científico al uso, en el lenguaje de las expertas sanitarias feministas que tantas novedades han producido estos años ${ }^{2}$, he optado por un libro popular y, en cierto modo, extra-académico ${ }^{3}$.

Del contradictorio perfil popular de El sentido de la enfermedad dan buena cuenta algunos datos documentales básicos. En el conjunto de las bibliotecas académicas españolas (REBIUN) hallamos 13 ejemplares de esta obra (10 de la primera edición de 2006 y 3 de la segunda de 2009) entre los 15 títulos totales de Jean Bolen, de los que hay 9 traducciones y 6 ediciones en inglés. A nivel internacional, de su producción científica no hay constancia en la prestigiosa e ineludible base de datos bibliográfica Medline/PubMed, aunque

2. Una muestra de ese nuevo saber feminista o con perspectiva de género son los informes oficiales ministeriales, las monografías de revistas especializadas y algunos estudios generales que han actuado como manuales, en ausencia de éstos. Entre los primeros se hallan los tres informes generados por el Observatorio de la Salud de la Mujer de la Agencia de Calidad del Ministerio de Sanidad y Consumo de los últimos años: Informe Salud y Género 2005, Madrid, Ministerio de Sanidad, 2007; Informe Salud y Género 2006. Las edades centrales de la vida, Madrid, Ministerio de Sanidad, 2008; Informe Salud y género 2007-08. Mujeres y hombres en las profesiones sanitarias. Madrid, Ministerio de Sanidad, 2009. Entre los segundos, han constituido verdaderos hito, en sus respectivas sociedades de especialistas los siguientes: el dossier de 1999 de la revista Dynamis, de historia de la medicina y la ciencia «Mujeres y salud: prácticas y saberes» coordinado por Monserrat Cabré Pairet y Teresa Ortiz Gómez; el monográfico de la revista Gaceta Sanitaria de mayo de 2004 coordinado por Lucía Artazcoz: «Desigualdades de género y salud» (Gac Sanit 2004, vol. 18 supl. 2, 92 páginas), y la monografía de 2008 de la Sociedad Española de Salud Publica y Administración Sanitaria, coordinada por Camen Borrell y Lucía Artazcoz: Investigación en Género y Salud (SESPAS monografías, 2008). En tercer lugar, han actuado como manuales: Perspectivas de género en salud. Fundamentos científicos y socio-profesionales de diferencias sexuales no previstas, Madrid, Minerva, 2001, el Programa de Formación de Formadores/as en Perspectiva de Género, coordinado Concha Colomer y $\mathrm{M}^{\mathrm{a}}$ Pilar Sánchez, y Mujeres, salud y poder de Carme Valls (CátedraFeminismos, 2009). Para una reflexión sobre las evidencias de la influencia del feminismo en la comunidad médica española remito a Miqueo (2008), donde subrayo, además, la existencia de una Red de Investigación de Salud y Genero (RISG), la Red de Mujeres Profesionales Sanitarias, atendida desde 1999 por el Centre d'Analisi i Programes Sanitaris (CAPS), y la revista Mujeres y salud (MyS), fundada y dirigida desde 1996 por Leonor Taboada.

3. Aunque para ello haya necesitado el permiso expreso de la coordinadora Teresa Ruiz Cantero y supuesto (solo supuesto, ay) la aquiescencia de la estimada Concha Colomer. 
hallamos 116 citas de 17 obras distintas de Jean Bolen en las revistas de alto factor de impacto (JCR) del área de psicología y origen norteamericano, según indica las bases de datos del Institute for Scientific Information (ISI- Web of Knowledge). Las obras más citadas en el mundo académico internacional desde 1979 han sido Diosas para cada mujer (47 citas), El tao de la psicología (20 citas), Los dioses de cada hombre (9 citas) y Diosas de la mujer madura (5 citas).

La difusión por internet de la obra de Bolen es extraordinaria. Los comentarios y citas a la obra de esta prestigiosa analista y profesora de la Universidad de California proceden de una gran variedad de entidades, especialmente: organizaciones de mujeres interesadas en el crecimiento personal o lucha contra la violencia, bibliotecas y centros de esoterismo, empresas del libro o de cosmética, talleres y seminarios de psicología, o de formación reglada en psicología empresarial. La iconografía que acompaña las citas y usos de la obra de Jean Bolen merece un estudio aparte. Es un excelente indicador de su valor social y público extra-académico (¿femenino popular tradicional?). Las siluetas femeninas evanescentes, las flores y el espacio sideral son elementos claves, integrados en composiciones de estética meliflua, antigua o poco desarrollada, de suavísimos colores pastel y líneas curvas entrelazadas; una estética que contradice la claridad y potencia de su discurso, o la sagaz elección que subyace a muchas de las portadas de sus libros traducidos a más de 20 idiomas ${ }^{4}$.

\section{Dignificar la enfermedad desde el paciente, desde el profesional}

Leer El sentido de la enfermedad. Un viaje del alma (original Close to the bone: life-threatening illness and the search for meaning), bien sea por placer o por necesidad, supone una experiencia íntima, personal, pues se trata de una "guía» para afrontar una enfermedad grave, propia o ajena. Como dice la autora, su intención con este libro es «ayudar y sanar, hacerte sentir más seguro, animarte a que confíes en tu sabiduría interior y a que seas enteramente fiel a lo que te dicta tu más profunda intuición». Pero quien esto plantea, rozando a veces el estilo de los «manuales de autoayuda» (de los que muchos huimos y yo también), es una «experta» que ha tenido una dilatada experiencia de acompañamiento profesional en la enfermedad, siendo este libro el resultado de una serie de conferencias y seminarios sobre el cáncer de mama. El mensaje central es que la enfermedad es una experiencia espiritual.

La autora parte del supuesto de que si no nos mantenemos en contacto con nuestra alma, nuestra existencia no podrá ser auténtica, productiva,

4. Visitar: (http://www.jeanbolen.com/books/foreign_translations.html)

Feminismo/s 18, diciembre 2011, pp. 309-321 
interdependiente, ni puede tener sentido; y que si somos propensos a expresar el dolor emocional y la soledad espiritual en forma de síntomas físicos, es muy probable que caigamos enfermos. La enfermedad constituiría una crisis para el espíritu porque el sufrimiento, la muerte o la invalidez sumergen en un tiempo de peligros y azares que plantea interrogantes sobre el sentido de la vida y pone a prueba los vínculos interpersonales establecidos. El impacto de una enfermedad mortal como el cáncer, infarto, sida, y muchas enfermedades crónicas o degenerativas se asemeja -dice la autora- a la piedra que cae en la superficie remansada de un lago en que la conmoción se proyecta en anillos concéntrico. Afecta a las relaciones entre personas, conmueve profundamente a los demás, implica potencialmente al paciente y cuantos se ven afectados en lo más profundo de sí mismos, en el alma. Por ello, la tesis principal que la autora plantea, y subrayo yo, es que la curación y recuperación puede depender tanto o más de la profundización de las relaciones y de la implicación con la propia vida espiritual que de la pericia médica o psiquiátrica.

Late en todo el libro una crítica radical al sistema sanitario en nuestra cultura: porque siendo la enfermedad un acontecimiento profundamente espiritual, en cambio todo parece concentrarse en la parte del cuerpo que ha enfermado, ha sido dañada, sufre una disfunción o permanece fuera de control. Lamenta esta psiquiatra que a menudo la perspectiva del médico sea semejante a la de un general ante la guerra: la enfermedad es el enemigo que ha de ser combatido y el cuerpo del paciente, el campo de batalla.

El libro está estructurado en 13 capítulos siguiendo el curso de «la experiencia de enfermar» (y no la «historia natural de la enfermedad» como en los tratados de patología, o «el proceso de descubrimiento» como en los artículos de investigación). Cada capítulo indaga, explora o acompaña cada fase del viaje de quien enferma, desde la inicial «la tierra se abre bajo nuestros pies» hasta la final, sea «la vida en suelo fértil», sea «cuando me llegue la hora, quiero estar consciente». Los títulos de los capítulos y subcapítulos son bien elocuentes del estilo de escritura y del conocimiento aportado por esta analista jungiana, es decir, expresivos del valor de las palabras e imágenes y arquetipos culturales como recursos terapéuticos, junto a la quimioterapia, la radioterapia o la cirugía: El viaje de Psique, Como carne podrida en un gancho, El desmembramiento de Procusto, La enfermedad como punto de inflexión, A veces necesitamos historias, Conexiones espirituales, Invocar a los ángeles: la oración, Recetar imaginación, Rituales, La representación del mito, Ayudar al prójimo y Meditaciones.

Los recursos terapéuticos que propone Jean Bolen son complementarios a los biomédicos convencionales, pero a veces exige la intromisión en los 
espacios sanitarios de pautas de conducta que solo tienen sentido en este otro paradigma, como ciertos «rituales» de carácter espiritual (no religiosos necesariamente) en los quirófanos o en las salas de quimioterapia. Hay tal variedad de recursos (que reconocemos como «nuestros de toda la vida» y eficaces) y tal juego de integración de muchos de ellos, y tanta perspicacia para deconstruir culturalmente los protocolos de actuación sanitaria convencionales, que el libro puede ser leído también como un excelente manual de descodificación del androcentrismo de la medicina. Aunque cada lector o lectora tiene su historia, sus experiencias, es fácil reconocer como propias muchas de las sugerencias terapéuticas que aporta y aprender sobre su universalidad y su probada eficacia.

Personalmente, me ha interesado mucho el capítulo décimo Recetar imaginación. Comienza situando el fenómeno del empleo terapéutico de la «visualización» y las «aserciones» en su medio ambiente profesional: «Mis compañeros médicos racionales se encogerán de hombros con esto, como ante mera incredulidad, o se enfurecerán como si fuera una tontería, pues desestiman o no toman en consideración los métodos para estimular la respuesta curativa del organismo. Su autoridad es intimidante, así como su convencimiento de que nada resulta efectivo a menos que sea químico e invasivo. Entiendo que este elemento de la medicina alopática es «cosa de hombres», con su énfasis en subyugar y conquistar la enfermedad. Quizá tenga que ver con tener atrofiado el hemisferio cerebral derecho y, por lo tanto, con la carencia de un enfoque desde la perspectiva curativa $\star^{5}$. Como ella afirma, son técnicas que vinculan mente y cuerpo, cuyos mecanismos bioquímicos conocemos imperfectamente, pero de los que hay estudios científicos que demuestran su eficacia terapéutica. Cuando visualizamos una metáfora se produce una reacción orgánica a nivel fisiológico; gracias a los «receptores peptídicos», los relatos que escuchamos, creemos y nos aplicamos a nosotros mismos se interiorizan profundamente e influyen en la mejoría y la curación. Dos ejemplos bastarán para comprender intuitivamente de qué habla Jean Bolen y su efecto terapéutico. Tras conseguir un estado de relajación ordenando a cada músculo que se distendiera y se imaginara a sí mismo en un lugar tranquilo y agradable, sentado al pie de un árbol, junto a un arroyo..., «el oncólogo pidió al paciente que se imaginara la radioterapia como una lluvia de diminutas partículas de energía que caían en la parte de su cuerpo arrasada por el cáncer. Las células normales de la zona también se verían afectadas, pero resistirían la radiación que mataría a las cancerígenas. En ese momento tenía que imaginar la llegada

\section{Página 183.}

Feminismo/s 18, diciembre 2011, pp. 309-321 
de los linfocitos, cómo se arremolinaban alrededor de las células cancerígenas debilitadas, las arrancaban y transportaban con las muertas o moribundas y las expulsaban del organismo ${ }^{6} »$. Para curar una artritis, «el paciente imaginó mentalmente que sus linfocitos pulían las articulaciones de sus brazos y piernas, eliminando todo residuo, hasta que las superficies quedaban limpias y relucientes ${ }^{7} »$. Por supuesto, los linfocitos pueden visualizarse como soldados que atacan y destruyen a los invasores. Pero también como «millones de microscópicos ángeles de la guarda que me protegían circulando a través de los tejidos de mi organismo, capaces de reconocer lo que no debía estar ahí y librarse de ello ${ }^{8}$.

Por supuesto, no es ella el primer «experto» en promover el uso terapéutico de la palabra y el relato. Como historiadora de la medicina conozco esta tradición, pero ni en la pionera y ya clásica síntesis La curación por la palabra en la antigüedad clásica del eminente Pedro Laín Entralgo publicada en 1958, ni en otras posteriores y de corte más antropológico que filosófico, se vislumbra la fuerza y universalidad de esta sabiduría femenina milenaria que trasmite Jean Shinoda Bolen, más entroncada -pienso yo, y por seguir en el mismo contexto- con el magistral Therapeia. La medicina popular en el mundo clásico de Luis Gil publicada en 1969. Creo que la propuesta de la académica Dra. Bolen es de otra estirpe cultural. En su obra reconozco mi genealogía femenina. Leerle me libera por un tiempo de esa pesarosa condición jánica de ser hoy mujer académica, mientras tomo conciencia de la orfandad materna de nuestra prestigiosa ciencia médica, la biomedicina.

\section{3. ¿Un estilo de escritura en femenino?}

El sentido de la enfermedad es como un manual de autoayuda en su intención, un texto científico en su estructura o discurso, y literario, algo poético, en su escritura. Un ejemplo de excelente divulgación científica en femenino.

La lectura comparada con otros manuales de autoayuda masculinos de cualquier campo de la vida profesional o personal -como, por ejemplo, Administre su tiempo eficazmente de Hochheiser, publicado hace poco más de una década, en el 2000 o Cómo escribir y publicar trabajos científicos de Robert Day pubñlicado en 1996- nos ofrece algunas claves de la diferencia sexual en el estilo de pensamiento y escritura científica. Pero aún más interesante resulta compararlo con otros excelentes textos de alta divulgación sobre la salud y

\footnotetext{
6. Página 187.

7. Página 188.

8. Páginas 189-190.
} 
enfermedad, planteados también desde el ámbito de la psicología y de similar éxito de público que el de Bolen, pero autoría masculina. Recomiendo, con esta intención, una relectura comparada del estilo de La fuerza del optimismo del psiquiatra Luis Rojas Marcos publicado en 2005, o Inteligencia emocional y El Punto ciego del psicólogo Daniel Goleman y publicados en 1996 y 1999 respectivamente. Es un ejercicio útil para observar y registrar los ingredientes del estilo retórico científico preferido por los hombres y por las mujeres en cuanto que autores, aun sabiendo ellos y ellas que sus principales lectores son, en realidad, lectoras.

A diferencia de los manuales de autoayuda para el éxito personal o profesional destinados a conseguir ciertos cambios de conducta personal en lo público, o los libros de divulgación de psicología o psiquiatría propios de la educación para la salud, éste de Jean Bolen tiene por objeto promover la confianza en la propia intuición, activar la introspección para descubrir la capacidad auto-sanadora por mediación del sistema psicoinmunitario. Está planteado desde unos presupuestos pedagógicos distintos de los habituales. No desde el poder del experto, la atalaya de quien todo lo sabe y condesciende a enseñar a otros cómo son las cosas o las recetas para lograrlo, sino desde la exquisita tradición de la madre-maestra destinada a guiar, es decir, a lograr «vivir la experiencia que enseña», con ejemplos, en este caso, traídos de la propia experiencia profesional y de la mitología. Concuerda con la tradición, y posición social masculina y científica, el escribir poniendo en juego sólo el conocimiento, los aspectos cognitivos del aprendizaje, y hacerlo desde el conocimiento científico acumulado por el autor y avalado, a cada paso, por las citas bibliográficas, como vemos en los citados de Daniel Goleman o Luis Rojas o Valentín Fuster (y en su excelencia, las diferencias observables entre ellos son reveladoras de su distinta personalidad, objetivo editorial y campo científico). Quizá sea lo femenino de la dra. Bolen lo que se expresa primordialmente en El sentido de la enfermedad. Un viaje del alma al poner en juego la emoción, buscando a cada paso la experiencia vital compartida, aquellas imágenes, mitos, palabras o sensaciones corporales que pueden conectar emocionalmente con el lector o lectora, transformándoles y garantizando la «incorporación» del nuevo saber. Todos, ellos y ellas, buscan lo universal del saber (científico), pero con recursos distintos.

El estilo de la Dra. Bolen recuerda tanto a María Zambrano en su Hacia un saber sobre el alma, aún en la simplicidad y pragmatismo propios de estos best seller norteamericanos, como a Mujeres que corren con lobos de Clarissa Pinkola y la legión de libros de autoayuda, medicina integral y crecimiento personal, más o menos esotéricos, que tanto gustan a las mujeres y se venden 
en las librerías heterodoxas y en tiendas de cosmética o alimentación natural. Y tan poco a nuestros ensayos científicos incluso feministas... La distinción tan habitual en nuestra comunidad científica entre las «ciencias duras» y las ciencias blandas» y su atribución de género -masculinas y femeninas, respectivamente- no es ajeno al estilo científico de aprendizaje y de enseñanza de unas y otras, ni a su vinculación con los métodos preferidos o aceptables (cuantitativos y cualitativos), ni al concepto de «evidencia» o el estatus epistemológico de la «subjetividad y singularidad» en unas y otras ciencias. Debemos discutir, con otros datos, de nuevo, las ventajas e inconvenientes del corsé del método científico y la supremacía epistémica de las ciencias biomédicas en el campo de la salud y la enfermedad y la marginalidad de las ciencias psico-sociales.

No siempre podemos gozar de las traducciones de women's studies escritos originalmente en inglés. La lectura en español que nos ofrece el traductor Antonio Francisco Rodríguez hace honor al cuidado que siempre ha puesto en ello la editoral Kairós, dirigida por Salvador Pániker, empeñada desde mediados de la década 1960 en la integración de lo oriental en nuestra occidental cultura cartesiana, tan poco sabia sobre el alma humana o el vacío o la quietud del kairos frente a la velocidad del Kronos, por nombrar algunas nociones claves. Solo encuentro un pero, y es menor y discutible. A mi me hiere (pero no me enfada) la elección en español de la palabra «ordalía», nada ocasional sino palabra clave en todo el libro de la dra. Bolen para referirse a esa «experiencia terrible» (la enfermedad constituye una ordalía); una palabra que en inglés usan en sentido figurado con frecuencia ( «exams are an ordeal»), pero que en español no solemos usar salvo para referirnos a situaciones próximas a los medievales juicios de Dios, las pruebas a las que eran sometidos «judicialmente» los reos para demostrar su inocencia; una durísima palabra que, yo recuerde, usó magistralmente Mercé Rodoreda en su última novela $\mathrm{La}$ muerte y la primavera (edición póstuma de 1986) para referirse a la «prueba de tránsito» a la vida adulta: un viaje iniciático a través del largo y tortuoso río subterráneo de un pueblo que debían realizar en la más completa oscuridad, ayudados por su memoria de la superficie conocida y sorteando las temibles raíces de las abundantes glicinas y las rocas naturales puntiagudas que podían enloquecer, mutilar o matar a los adolescentes que querían/debían probar su hombría. Pero aun contando con la mediación de tan estimada maestra, pienso si la dureza de esta palabra «ordalía» en nuestro español no estará traicionando el estilo de escritura elegido por la autora.

Aunque el objeto del libro sea trágico (la enfermedad grave, mortal o invalidante) y la principal hipótesis sea que la enfermedad es una ordalía y una 
ocasión para vivir plenamente, el tono de la escritura de Jean Shinoda Bolen no es dramático sino natural, dulce, suave, sin quebrantos, abstractos ni tonterías. Pongo un ejemplo especialmente interesante para nosotros, investigadores o enseñantes y lectores: «La enfermedad nos aparta de nuestra mente y nos centra en nuestro organismo. El mundo superior que abandonamos es también la claridad mental de nuestro ser anterior. El dolor y los medicamentos, el temor y la depresión, los efectos secundarios de tener una enfermedad mortal y seguir un tratamiento afectan a la memoria, a la apreciación de los detalles, a la capacidad de pensar con claridad, a la concentración y la atención a temas intelectuales. La enfermedad amenaza tanto la vida como la mente ${ }^{9}$ ». En «La enfermedad como punto de inflexión» (capítulo sexto), y tras sugerir que la enfermedad puede expresar un «fuego creativo frustrado», leemos: «Hemos de recuperar las fuentes de placer que yacen despedazadas, olvidadas y enterradas en el inframundo. Allí podemos encontrar las semillas de la creatividad, los talentos no cultivados, los vedados anhelos, los sueños abortados y la ecuanimidad ${ }^{10}{ }_{\text {}}$.

Un estilo oral de escritura. «Me lo imagino leído en voz alta», decía su autora en la introducción de El sentido de la enfermedad, título al que en la segunda edición de 2006, añadió significativamente: Un viaje del alma. Anglosajón, sin el rosario de subordinadas que acostumbramos en español, su lectora en voz alta resulta factible y agradable. Sin ese nivel de abstracción, codificación y corsé estructural del ensayo científico, su lectura resulta atractiva como una novela de suspense. La profusión de imágenes literarias no eruditas (que no remiten a otros libros que contienen otros libros) y que rozan el núcleo mítico ancestral de cada quien, tantas imágenes encarnadas que nos traen directamente experiencias vividas o vislumbradas hacen que su lectura se convierta en una aventura íntima intensa: en un rato pueden desfilar muchas escenas de la propia vida, y hay que dejar de leer, aquietar el alma. A diferencia de los ensayos masculinos propuestos para el análisis comparado, el estilo oral de éste resulta evidente. Tanto que puede ser utilizado fragmentariamente, como gusta a muchas mujeres, en conversaciones de café, tertulias, seminarios y clases. El número de moléculas literarias por metro cuadrado de libro (que podrían conformar eslóganes, axiomas, rótulos publicitarios, mantras, títulos de libros, o verdaderas verdades) es infinitamente superior al que hallamos en los citados autores masculinos. Hay libros que destilan vida pensada, y libros que destilan conocimiento adquirido. Este es de los primeros.

9. Página 88.

10. Página 101.

Feminismo/s 18, diciembre 2011, pp. 309-321 
En conclusión, la relectura de El sentido de la enfermedad. Un viaje del alma me confirma que la creación de conocimiento diferente, escindido, separado en dos instituciones simbólicas, la científica «convencional» de los hombres y la «alternativa» de las mujeres no es la solución para el mundo (postpatriacal) que habitamos. Me reafirma la idea de fomentar la lectura de obra literaria y mitológica, escrita o audiovisual, entre los estudiantes y futuros médicos; poblar su alma de palabras imprecisas que evoquen vivencias humanas reales, ancestrales y actuales, distrayendo así a sus neuronas de tantas cifras y datos exactos y precisos sobre el dichoso cuerpo. De la lectura de este libro de Jean Bolen infiero que es urgente apoyar a muchas profesionales sanitarias que están proponiendo reducir gasto sanitario por progresiva sustitución de «fármacos» por «palabras»; parece una iniciativa sensata, necesaria, además de la sabia corrección de un extravío -más masculino que femenino- de siglos ${ }^{11}$.

11. Entiendo que tejer ese paño no debe ser fácil si pienso en la tensión que ha generado en mí misma cruzar el umbral que significaba elegir este libro -que yo había adquirido en una tienda alternativa para un uso privado no académico- como objeto de una reseña pública, en tanto que historiadora de la medicina, profesora de metodología científica y documentación. He necesitado recuperar-reasignando significados- fragmentos de mi trayectoria intelectual y afectiva. A la niña que odiaba el huerto medicinal de su abuela porque tenía que regarlo a pozales que pesaban mucho y se mojaba a cada paso las zapatillas (eran otros tiempos), pero le gustaba llevar sus emplastos, pucheros o yogures a las casas del pueblo porque le hacía sentir especial, la nieta de una persona respetada en su comunidad. A la joven que despreciaba por antiguos, simples o acientíficos los remedios y soluciones que les ofrecía su madre, siempre remisa o desconfiada de la ciencia de los médicos (entonces no había médicas). A la estudiante de medicina de último curso que aprendió a respetar la diversidad de rutas de búsqueda de la curación de la mano de los historiadores de la medicina, en el contexto de la coexistencia de sistema médicos y el valor de la medicina popular, que desdeñaba por folclórica y supersticiosa. A la historiadora que fundamentó racionalmente su distancia epistemológica del saber femenino tradicional, retrasando la conciencia y aceptación de las insuficiencias de la medicina occidental: su reduccionismo analítico y su esencial androcentrismo. A la profesora que leía en clase textos de Rojas cuestionando recursos aquí propuestos. A la adulta amiga de muchas mujeres (más que hombres) que usan o practican confiadamente aromaterapia, cromoterapia, quiropráctica, musicoterapia, homeopatía, iridología, hierbas, libros de poesía, libros de autoayuda, hablan constantemente de energía, equilibrio y sanación, sintiéndose sabias dueñas de su cuerpo y alma. A la persona, en fín, que ha acompañado (y a veces ignorado) a personas muy queridas que han enfermado y fallecido o se han curado o convertido en enfermos crónicos. 


\section{Referencias bibliográficas}

BOLEN, Jean Shinoda. El sentido de la enfermedad. Un viaje del alma, Barcelona, Kairós, 2006.

DAY, Robert A. Cómo escribir y publicar trabajos científicos. $2^{a}$ ed. Washington, Organización Panamericana de Salud, 1996.

FUSTER, Valentín. La ciencia de la salud: mis consejos para una vida sana, Barcelona, Planeta, 2006.

GIL, Luis. Therapeia. La medicina popular en el mundo clásico, Madrid, Guadarrama, 1969.

Goleman, Daniel. El Punto ciego. Psicología del autoengaño, Madrid, Plaza y Janés, 1999.

Goleman, Daniel. Inteligencia emocional. 59ª ed. Barcelona, Salvat, 2005 ( $1^{\mathrm{a}}$ edición española: Kairos, 1996)

HoCHHEISER, Robert M. Administre su tiempo eficazmente, $2^{\mathrm{a}}$ ed. Plaza y Janés, 2000.

Laín Entralgo, Pedro. La curación por la palabra en la antigüedad clásica. $2^{a}$ ed., Barcelona, Anthropos, 1987.

MiqueO, Consuelo. "¿Feminismo en la comunidad científica médica española?» Isegoría 38 (2008), pp. 155-167.

Pinkola Estes, Clarissa. Mujeres que corren con los lobos, Barcelona, Ediciones B, 2000.

RODOREDA, Mercè. La muerte y la primavera, Barcelona, Seix Barral, 1986.

Rojas MARCos, Luis. La fuerza del optimismo. Madrid, Aguilar, 2005.

Zambrano, María. Hacia un saber sobre el alma, Madrid, Alianza, 1987.

Feminismo/s 18, diciembre 2011, pp. 309-321 